\title{
A atuação do pediatra no aleitamento materno em uma cidade do interior paulista
}

\author{
The performance of the pediatrics in breastfeeding in a city of the paulista interior \\ El desempeño del pediatrico en lactancia en una ciudad de la paulista interior
}

Tereza Lais Menegucci Zutin ${ }^{1 *}$, Juliana Rejane da Silva Roque ${ }^{1}$, Luis Felipe Silva Pimenta², Flavia Vilas Boas Ortiz Carli ${ }^{1}$, Heron Fernando de Sousa Gonzaga ${ }^{1}$, Camila Pires Cabelo Menegucci ${ }^{1}$, Mariana Cadelca Zalbinate ${ }^{1}$, Thais Menegucci ${ }^{1}$, Maria Eduarda Moris ${ }^{1}$, Maria Lúcia Jorge Gonzaga ${ }^{1}$.

\section{RESUMO}

Objetivo: Descrever o conhecimento dos pediatras à respeito do aleitamento materno. Métodos: Trata-se de um estudo transversal, realizado no serviço público de saúde com uma amostra composta por 15 pediatras. Para a coleta de dados foi utilizado um formulário com perguntas assertivas acerca de aleitamento. Resultados: Em relação ao tipo de mamilo, 40\% afirmaram a interferência do mesmo no processo de amamentação, outros $40 \%$ negaram e $20 \%$ não souberam responder. No que diz respeito a contra indicações do aleitamento materno, 53,33 afirmaram que mães infectadas com o vírus da hepatite $\mathrm{B}$ e $\mathrm{C}$ e portadoras de doenças graves e/ou crônicas não podem amamentar.Quanto aos direitos dos pais, $40 \%$ afirmaram que são concedidos dois períodos distintos de uma hora cada um para o aleitamento até que o bebe complete um ano de vida. Conclusão: Foi observada uma defasagem do conhecimento em relação a anatomia das mamas, às contra indicações do aleitamento materno e aos direitos da mãe e do pai durante o período de amamentação.

Palavras-chave: Aleitamento materno, Consulta médica, Pediatria.

\begin{abstract}
Objective: To describe the knowledge of pediatricians regarding breastfeeding. Methods: This is a crosssectional study, carried out in the public health service with a sample composed of 15 pediatricians. For data collection, a form with assertive questions about breastfeeding was used. Results: Regarding the type of nipple, $40 \%$ stated that it interfered with the breastfeeding process, another $40 \%$ denied it and $20 \%$ did not know how to respond. With regard to contraindications to breastfeeding, 53.33 stated that mothers infected with the hepatitis $B$ and $C$ virus and carriers of serious and / or chronic diseases cannot breastfeed. As for the rights of parents, $40 \%$ stated that they are Two distinct periods of one hour each are allowed for breastfeeding until the baby is one year old. Conclusion: There was a lack of knowledge regarding the anatomy of the breasts, the contraindications for breastfeeding and the rights of the mother and father during the breastfeeding period.
\end{abstract}

Keywords: Breastfeeding, Medical consultation, Pediatrician.

\section{RESUMEN}

Objetivo: Describir los conocimientos de los pediatras sobre la lactancia materna. Métodos: Se trata de un estudio transversal, realizado en el servicio de salud pública con una muestra compuesta por 15 pediatras.

\footnotetext{
${ }^{1}$ Universidade de Marília (UNIMAR). Marília - São Paulo. *E-mail: lais_zutin@hotmail.com

${ }^{2}$ Maternidade Santa Isabel (FAMESP). Bauru - São Paulo.
} 
Para la recolección de datos se utilizó un formulario con preguntas asertivas sobre la lactancia materna. Resultados: En cuanto al tipo de pezón, el $40 \%$ afirmó su interferencia en el proceso de lactancia, otro 40\% lo negó y el $20 \%$ no supo responder. En cuanto a las contraindicaciones para la lactancia materna, 53,33 afirmaron que las madres infectadas por el virus de la hepatitis $B$ y $C$ y con enfermedades graves y / o crónicas no pueden amamantar. En cuanto a los derechos de los padres, el $40 \%$ manifestó que son Se permiten dos períodos distintos de una hora cada uno para amamantar hasta que el bebé tenga un año. Conclusión: Existió un desconocimiento sobre la anatomía de las mamas, las contraindicaciones para la lactancia materna y los derechos de la madre y el padre durante el período de lactancia.

Palavra clave: Lactancia maternal, Consulta médica, Pediatra.

\section{INTRODUÇÃO}

O aleitamento materno exclusivo, segundo o Ministério da Saúde (MS), é recomendado até o sexto mês de vida. Este é o vínculo entre a mãe e a criança, além de diminuir a mortalidade infantil, por diarreia e por infecções respiratórias, diminuir alergias, doenças crônicas, obesidade, melhorar a nutrição, desenvolvimento cognitivo, desenvolvimento da cavidade bucal e proteção contra câncer de mama (LEVY L e BERTOLO H, 2008).

A baixa aderência ao aleitamento materno exclusivo constitui um problema de saúde pública, sendo necessária intervenção na perspectiva de estimular as políticas nacionais de apoio ao aleitamento materno (BRASIL, 2015). No entanto, o incentivo à amamentação deve vir de uma equipe multiprofissional de apoio, no qual o pediatra tem o exime papel na assistência à mãe e à criança, sendo indispensável à interação com os outros profissionais (CAMPOS DJ e BURNS DAR, 2014).

O profissional de saúde tem a responsabilidade de criar condições favoráveis a uma relação interpessoal efetiva mostrando-se genuinamente interessado, de tal modo que a nutriz se perceba objeto de sua atenção e, assim, sinta-se confortável e estimulada a engajar-se na relação (REZENDE MA, et al., 2002).

Contudo, cabe a este profissional, identificar e compreender o processo do aleitamento materno no contexto sociocultural e familiar, uma vez que este precisa estar preparado para prestar uma assistência eficaz, solidária, integral e contextualizada, que respeite o saber e a história de vida de cada mulher (ARAÚJO RMA e ALMEIDA JAG, 2007).

A sociedade, que ainda impõe à mulher uma alta carga de responsabilidade de cuidados com a família, também precisa dar importância ao papel dos homens e prepará-los para a paternidade e para a sua participação na construção do ambiente doméstico colaborativo, onde os parceiros possam ter disposição e amparo para exercer não só suas obrigações, mas suas posições naturais de forma prazerosa e feliz (ZUTIN TLM, 2012).

O estudo de Sandes AR, et al. 2007, aponta como causa do desmame precoce, a desinformação da população e, também dos profissionais da área de saúde. A difusão de informações errôneas é equivalente às mães que abandonam a amamentação, o que torna evidente a importância da capacitação dos profissionais de saúde e da ação destes diante de tal situação.

De acordo com a Sociedade Brasileira de Pediatria (2017), dentre os tantos benefícios do aleitamento materno exclusivo para a criança verifica-se concomitantemente benefícios à família como um todo, o que torna evidente a necessidade descrever o conhecimento dos pediatras à respeito do aleitamento materno de firmar a importância do profissional nesta assistência. Esse estudo tem como objetivo descrever o conhecimento dos pediatras, atuantes na rede pública, à respeito do aleitamento materno

\section{MÉTODOS}

Trata-se de um estudo Transversal, quantitativo de caráter exploratório e descritivo. A população alvo foi constituída de pediatras atuantes no serviço público de saúde, em um município de São Paulo. A amostra foi 
constituída por 15 pediatras, sendo utilizado como critério de inclusão a atuação na especialidade de pediatria na rede pública do município.

Para coleta de dados utilizou-se um questionário validado, o qual foi adaptado e é composto por questões abertas e fechadas a respeito do aleitamento materno, as quais foram agrupadas em: caracterização da amostra, vantagens do aleitamento materno, anatomia das mamas e fisiologia da lactação, técnicas de amamentação, contra indicações da amamentação, desmame precoce e direitos do casal durante a amamentação.

A coleta de dados foi realizada no período de agosto de 2018 a agosto de 2019 e os dados foram analisados por meio do programa SPSS v. 20. O projeto de pesquisa foi aprovado pela Comissão de Ética em Pesquisa da Universidade de Marília (CEP) e aprovado na Plataforma Brasil com parecer de número 86670218.8.0000.5496.

\section{RESULTADOS}

Os dados apresentados integram informações acerca da amostra pesquisada com características relativas a algumas variáveis sócio demográficas (Tabela 1). Foi verificado que, dos 15 pediátras entrevistados, a maioria $(73,3 \%)$ são do sexo feminino, casados $(73,3 \%)$, com idade variando entre 30 e 59 anos.

Tabela 1 - Caracterização da amostra.

\begin{tabular}{llc}
\hline Variável & N & Valor (\%) \\
\hline Sexo & 11 & 73,33 \\
\hline Feminino & 4 & 26,67 \\
\hline Faixa etária & & \\
\hline 30 a 39 anos & 5 & 33,33 \\
40 a 49 anos & 3 & 20 \\
50 a 59 anos & 4 & 26,67 \\
60 anos ou mais & 3 & 20 \\
\hline Estado civil & 11 & 73,33 \\
\hline Casado (a) & 1 & 6,67 \\
Solteiro (a) & 3 & 20 \\
Divorciado (a) & & \\
\hline
\end{tabular}

Fonte: Zutin TLM, et al., 2020.

Em relação ao tempo de formação, a grande maioria (93,3\%) desses profissionais possuem 7 anos ou mais de formados, sendo que, quase metade dos pediatras atuam na Atenção Primária (46,67\%) e com uma formação predominante em residência médica (73,33\%) (Tabela 2). 
Tabela 2 - Dados quanto a formação.

\begin{tabular}{lcc}
\hline Variável & N & Valor (\%) \\
\hline Tempo de formado & & \\
\hline 1 a 3 anos & 1 & - \\
4 a7 anos & 14 & 6,67 \\
7 anos ou mais & & 93,33 \\
\hline Local de trabalho & 7 & 46,67 \\
\hline UBS / USF & 1 & 6,67 \\
Consultório & - & - \\
Hospital & 6 & 40 \\
Consultório / hospital & 1 & 6,67 \\
UBS / USF, Consultório, Hospital & & \\
\hline Categoria de formação & 3 & 20 \\
\hline Especialização & 11 & 73,33 \\
Residência & 1 & 6,67 \\
Especialização / Residência
\end{tabular}

Legenda: UBS - Unidade Básica de Saúde; USF - Unidade de Saúde da Família. Fonte: Zutin TLM, et al., 2020.

Em relação ao número de filhos observamos que $33,33 \%$ dos entrevistados tiveram dois filhos. Quando questionadas sobre já ter amamentado obtivemos uma resposta positiva em $66,67 \%$ e $60 \%$ referiram planejamento de amamentar antes da gestação. Ao questionar a razão que as levaram a amamentar, a alternativa sem resposta predominou. E em detrimento sobre algum conhecimento sobre o aleitamento materno obtivemos a totalidade de $100 \%$.

Em sequência, no questionamento sobre o período ideal para fazer aleitamento materno exclusivo encontramos supremacia até 6 meses com $66,67 \%$, em contrapartida obtivemos a alternativa não sabe ou sem resposta ambos em $13,33 \%$ e $13,33 \%$ enquanto a mãe estiver produzindo leite materno. Referente a quem o aleitamento materno pode beneficiar, $73,33 \%$ mencionaram o pai, a mãe, a família e a sociedade.

A totalidade dos pediatras entrevistados afirmaram que o recém nascido deve ser mantido junto à mãe desde o nascimento para favorecer a liberação do leite e que a primeira mamada do bebê deve ser na primeira hora de vida, sendo que, o leite materno contém todos os nutrientes que o bebê necessita nos primeiros seis meses de vida, e quanto as vantagens do leite materno todos afirmaram que o mesmmo é o alimento mais adequado às necessidades do bebê, pois possui melhor digestibilidade, previne o risco de algumas infecções e alergias, promove a linguagem do bebê e diminui problemas de alteração morfológica da boca, e é fator de proteção à obesidade. Em vista ao questionamento da amamentação deixar as mamas descaídas predominou a resposta negativa em $86,67 \%$. A maioria dos entrevistados afirmou que o pai possui um papel primordial no sucesso da amamentação. A maioria dos pediatras $86,6 \%$, afirmaram que bebês que são amamentados possuem um coeficiente de inteligência emocional mais alto, e diminuição do risco de diabetes tipo I e linfomas.

Em referência às vantagens do aleitamento materno para a mãe foi encontrado um percentil de $93,3 \%$ que referiram promover involução uterina precoce e perda de peso mais rápida. Já no questionamento sobre diminuir o risco de câncer de mama e ovários o percentil foi de $86,67 \%$, ao indagar o favorecimento do vínculo 
entre a mãe e filho foram encontrados $100 \%$ de respostas positivas, e ao contestar se a amamentação exclusiva protege a mãe de gravidez obtivemos $46,67 \%$ afirmando tal questionamento.

Ao questionarmos sobre as vantagens do aleitamento materno para a família deparamos com $100 \%$ das respostas confirmando o fato de ser mais econômico.Em relação às vantagens do aleitamento materno para a sociedade concluiu-se que perde-se menos tempo em trabalho baseado em um percentil de $66,67 \%$, e que diminui-se os custos ao atendimento de saúde em $100 \%$ das respostas.

No tocante das vantagens do aleitamento materno para o meio ambiente, com a porcentagem de $86,67 \%$ conclui-se que há uma redução de custos por diminuir o consumo de recursos ambientais, diminuir a industrialização do material e os desperdícios e diminuir a poluição ambiental. Já indagar se a amamentação é um ato ecológico percebeu-se um percentil de 93,33\% em resposta afirmativa. No entanto, ao analisar outras vantagens do aleitamento materno, o fato de estar sempre pronto a servir, de encontrar-se à temperatura ideal e por ser mais prático teve um consenso de 100\% nas respostas.

Em relação ao conhecimento da anatomia e fisiologia da mama, 100\% referiu que tanto pode amamentar uma mulher com mamas grandes quanto com mamas pequenas. A grande maioria dos pediatras afirmaram que o hormônio prolactina e a sucção eficaz estão relacionados com o aumento na produção de leite materno. Todavia, ao indagar sobre a interferencia do tipo de mamilo no sucesso da amamentação encontramos uma divergência nas respostas, pois $40 \%$ afirmando interferência no processo de amamentação, outros $40 \%$ negando e $20 \%$ relatando que não sabem (Tabela 3 ).

Ainda perante a técnica de amamentação, 93,3\% afirmaram que se deva lavar sempre as mãos antes de iniciar a amamentação e que as mamas devem ser lavadas diariamente durante o banho sem produtos agressivos, e no fim devem ser colocadas gotas de leite no mamilo e em volta dele. No que diz respeito à posição correta para promover a pega correta, e à livre demanda da amamentação a totalidade dos entrevistados afirmaram tais interrogativas e 60\% afirmaram a importância do tempo de mamada.

Tabela 3 - Conhecimento de anatomia e fisiologia das mamas.

\begin{tabular}{|c|c|c|c|c|}
\hline Questões & Sim & Não & Não Sei & Total \\
\cline { 2 - 5 } & $\mathbf{N} / \%$ & $\mathbf{N} / \%$ & $\mathbf{N} / \%$ & $\mathbf{N} / \%$ \\
\hline $\begin{array}{c}\text { Tanto pode amamentar uma mulher com mamas } \\
\text { grandes como outra com mamas pequenas }\end{array}$ & $15 / 100$ & - & - & $15 / 100$ \\
\hline $\begin{array}{c}\text { O tipo de mamilo não interfere no sucesso da } \\
\text { amamentação }\end{array}$ & $6 / 40$ & $6 / 40$ & $3 / 20$ & $15 / 100$ \\
\hline $\begin{array}{c}\text { A produção do leite deve-se a uma hormônio } \\
\text { chamada prolactina }\end{array}$ & $14 / 93,33$ & $1 / 6,67$ & - & $15 / 100$ \\
\hline $\begin{array}{c}\text { A ocitocina é um hormônio que estimula a } \\
\text { libertação do leite }\end{array}$ & $14 / 93,33$ & $1 / 6,67$ & - & $15 / 100$ \\
\hline $\begin{array}{c}\text { Sempre que o bebê suga na mama aumenta a } \\
\text { produção do leite }\end{array}$ & $15 / 100$ & - & - & $15 / 100$ \\
\hline $\begin{array}{c}\text { Para aumentar a produção do leite, a criança deve } \\
\text { sugar eficazmente na mama }\end{array}$ & $15 / 100$ & - & - & $15 / 100$ \\
\hline
\end{tabular}

Fonte: Zutin TLM, et al., 2020.

A totalidade dos entrevistados responderam que mães que precisam tomar medicamentos nocivos à criança e mães infectadas com o vírus do HIV não podem amamentar seus filhos. Já em relação a mãe com tuberculose ativa, $81,25 \%$ afirmaram que a amamentação também é contraindicada. 
Quando questionados sobre a interrupção precoce da amamentação obtivemos predominância de 93,33\% afirmando relação com o fato da mãe pensar ter pouco leite, ter problemas com as mamas e o regresso ao trabalho, todavia obtivemos $86,67 \%$ alegando que o bebê chora muito (Tabela 4).

Tabela 4 - Contra indicações do aleitamento materno.

\begin{tabular}{|c|c|c|c|c|}
\hline Questôes & Sim & Não & Não Sei & Total \\
\cline { 2 - 5 } & $\mathbf{N} / \%$ & $\mathbf{N} / \%$ & $\mathbf{N} / \%$ & $\mathbf{N} / \%$ \\
\hline Doença grave, crônica ou debilitante da mãe & $8 / 53,33$ & $7 / 46,67$ & - & $15 / 100$ \\
\hline $\begin{array}{c}\text { Mães que precisem de tomar medicamentos nocivos } \\
\text { à criança }\end{array}$ & $15 / 100$ & - & - & $15 / 100$ \\
\hline $\begin{array}{c}\text { Mãe com tuberculose ativa } \\
\text { Mãe infectada com vírus do HIV }\end{array}$ & $13 / 86,67$ & $2 / 13,33$ & - & $15 / 100$ \\
\hline Mãe infectada com vírus hepatite B e hepatite C & $8 / 53,33$ & $6 / 40$ & $1 / 6,67 z$ & $15 / 100$ \\
\hline $\begin{array}{c}\text { Bebê com transtornos metabólicos (fenilcetunúria e } \\
\text { galactosémia) }\end{array}$ & $11 / 73,33$ & $3 / 20$ & $1 / 6,67$ & $15 / 100$ \\
\hline
\end{tabular}

Fonte: Zutin TLM, et al., 2020.

Em relação aos direitos da mãe e do pai no processo de amamentação, a maioria julgou correta tais afirmações: a licença maternidade no Brasil é de 120 dias, o direito da mãe em ser dispensa do trabalho, por dois períodos distintos de duração máxima de uma hora, durante todo o tempo que durar a amamentação do/a filho/a, sem perda de remuneração ou regalias e afirmaram que em situação de gravidez, a gestante têm o direito à proteção no despedimento das durante a licença maternidade ou de amamentação (Tabela 5).

Tabela 5 - Direitos dos pais.

\begin{tabular}{|c|c|c|c|c|}
\hline Questões & Correta & Incorreta & Não sei & Total \\
\cline { 2 - 5 } & $\mathbf{N} / \%$ & $\mathbf{N} / \%$ & $\mathbf{N} / \%$ & $\mathbf{N} / \%$ \\
\hline A licença de maternidade no Brasil é de 120 dias & $12 / 80$ & $2 / 13,33$ & - & $15 / 100$ \\
\hline São acrescidos 30 dias por cada gêmeo além do primeiro & $5 / 33,33$ & $9 / 60$ & $1 / 6,67$ & $15 / 100$ \\
\hline $\begin{array}{c}\text { Direito da mãe de dispensa do trabalho, por dois } \\
\text { períodos distintos de duração máxima de uma hora, } \\
\text { durante todo o tempo que durar a amamentação do/a } \\
\text { filho/a, sem perda de remuneração ou regalias }\end{array}$ & $13 / 86,67$ & $2 / 13,33$ & - & $15 / 100$ \\
\hline $\begin{array}{c}\text { Direito da mãe e/ou do pai trabalhador, por decisão } \\
\text { conjunta, a dispensa do trabalho por dois períodos } \\
\text { distintos de uma hora cada um para aleitamento do/a } \\
\text { filho/a até este/a completar um ano, sem } \\
\text { perda de remuneração ou de regalias }\end{array}$ & $6 / 40$ & $8 / 53,33$ & $1 / 6,67$ & $15 / 100$ \\
\hline $\begin{array}{c}\text { Direito à proteção no despedimento das trabalhadoras } \\
\text { em situação de gravidez, de licença por maternidade ou } \\
\text { de amamentação }\end{array}$ & $13 / 86,67$ & $1 / 6,67$ & $1 / 6,67$ & $15 / 100$ \\
\hline \begin{tabular}{c} 
A licença de paternidade no Brasil é 20 dias \\
\hline
\end{tabular} & $3 / 20$ & $10 / 66,67$ & $2 / 13,33$ & $15 / 100$ \\
\hline
\end{tabular}

Fonte: Zutin TLM, et al., 2020. 


\section{DISCUSSÃO}

Segundo a Organização Mundial da Saúde (2000), o aleitamento materno deve ser exclusivo até os seis meses de idade e mantido até os 2 anos ou mais. No primeiro semestre de vida, o leite materno é capaz de suprir todas as necessidades da criança (MELO CS e GONÇALVES RM, 2014). O estudo de Sousa PKS, et al. (2020), relata que a amamentação das crianças da amostra na primeira hora de vida foi significativamente associado ao recebimento de orientações no pré-natal e alojamento conjunto. Dessa forma, o presente estudo também confirma a opnião de pediatras sobre exclusividade do aleitamento, a presença de nutrientes e de sua importância para a criança.

Com o processo de amamentação, as mamas ficam descaídas por conta do desmame precoce, caso ele seja interrompido ou pelo fato de não amamentar, segundo Lothrop $H(2000)$, contrapondo as respostas encontradas no estudo, negando o decaimento das mamas.

Com relação ao papel paterno no sucesso da amamentação foi observada a importância da participação do pai atuando no bem estar psíquico e social da mãe encorajando a lactação como parceiro (ZUTIN TLM, 2012). Marques ES, et al. (2010), aponta que a presença do pai tem um papel mais importante em relação aos outros familiares, tendo uma maior relevância para a amamentação, sendo influenciador da decisão da mãe em amamentar e sua continuidade. Os pediatras entrevistados no presente estudo, afirmaram também, que a atitude do pai em relação à mãe e ao aleitamento interfere no sucesso do aleitamento.

O aleitamento materno protege contra as infecções respiratórias e gastrointestinais, diminui também o risco de alergias, hipertensão arterial, diabetes, leucemia, hipercolesterolemia e obesidade devido às imunoglobulinas e nutrientes presentes no leite materno (RABELO DA, 2017). A amamentação pode prevenir $50 \%$ de todos episódios de diarreia e 33\% das infecções respiratórias (HORTA BL, et al., 2015).

O aleitamento manterno é responsável pela redução de $26 \%$ na probabilidade de desenvolver obesidade ou sobrepeso ao mesmo tempo que reduz em até $56 \%$ a chance de ocorrer diabetes tipo 2 e $19 \%$ na incidência de leucemia na infância (AMITAY EL e KEINAN-BOKER L, 2015). A maioria dos pediatras afirmaram que bebês que são amamentados possuem um coeficiente de inteligência emocional mais alto, e diminuição do risco de diabetes tipo I e linfomas.

Ademais, o aleitamento atua no desenvolvimento da cavidade bucal, já que 0 ato de sucção pode determinar o desenvolvimento motor-oral harmônico, influenciando positivamente na mastigação, deglutição, respiração e fala concordando com os interrogados (NEIVA FCP, et al., 2003). Estima-se que crianças amamentadas por mais tempo, tiveram uma redução de $68 \%$ na chance de má oclusão dentária (PERES KG, et al., 2015). E no quesito do coeficiente de inteligência, Victora CG, et al. (2015), concluiu que amamentação por mais de 12 meses promove um QI com valores superiores a 3,76 pontos em relação aos demais que não foram amamentados, $86,67 \%$ dos entrevistados concordando com tal benefício.

Ao indagar sobre as vantagens do aleitamento materno ao lactente verificou-se a garantia de uma nutrição balanceada, contendo todos os macro e micronutrientes necessários. Assim sendo, nele contém a caseína, uma proteína responsável pela digestibilidade, a qual é essencial nesta fase de imaturidade gastrointestinal (EUCLYDES M, 2005; LUSTOSA E e LIMA RN, 2020).

Por outro lado, o aleitamento materno garante proteção à mãe contra câncer de mama, câncer de ovário, diabetes, fraturas ósseas, e morte por artrite reumatoide (BRASIL, 2015). No presente estudo, $86,67 \%$ dos questionados evidenciaram tal benefício. Segundo Brasil (2015), o aleitamento materno também proteje a mãe contra a gravidez nos primeiros meses após o parto, como também promove a perda rápida de peso da mãe e favorece o vínculo mãe e filho gerando proteção, segurança e confiança.

Segundo Joca MT, et al. (2005), as mulheres estudadas vivem em situação de miséria, sendo o aleitamento materno uma prática que garante a saúde do bebê sem gasto financeiro por parte da família, o que torna o aleitamento materno vantajoso para a família. Assim, os profissionais questionados concordaram em sua totalidade com esta afirmativa. Os pais perdem menos tempo de trabalho com os filhos que foram amamentados devido ao aleitamento materno proporcionar a redução de doenças, e consequentemente 
diminuir os custos com atendimento à saúde uma vez que torna esses bebês mais saudáveis (ALDEN KK, 2002). No entanto, somente $66,67 \%$ dos entrevistados condizem com o fato de perder menos tempo de trabalho.

Além do fator econômico familiar, o aleitamento materno interfere na economia mundial. Se $10 \%$ a mais de crianças fossem amamentadas por pelo menos 6 meses ou até 12-24 meses, seria gerado uma economia de 1,8 milhão de dólares para o Brasil em relação ao tratamento de morbidade infantil relacionada à não amamentação (podendo alcançar 6 milhões se houvesse uma melhora de 90\%). No mundo 302 bilhões de dólares poderiam ser evitando os déficits cognitivos associado às práticas de amamentação inadequada (ROLLINS NC, et al., 2016).

Com relação às vantagens do aleitamento materno para o meio ambiente, $86,67 \%$ dos entrevistados afirmaram reduzir os custos devido a diminuição do consumo de recursos ambientais, diminuir a industrialização do material e desperdícios, e também a poluição ambiental, uma vez que as mamadeiras e bicos, as latas e os rótulos são feitos de vidro, borracha, silicone e papel contribuindo com a poluição na produção e distribuição do produto, criando acúmulo de lixo (ARAÚJO MFM, et al., 2004). Ao serem indagados sobre a amamentação ser um ato ecológico, 93,33\% afirmaram tal suposição.

O recém nascido deve estar em contato com a mãe desde sua primeira hora de vida, para que haja o estímulo da amamentação, já que a sucção do mamilo estimula a liberação do leite materno, o que reforça o resultado obtido em sua totalidade (BARBOSA LA, 2017).

Com relação a fisiologia da lactação e anatomia da mama, sabe-se que cerca de 30 a 40 horas após o parto se inicia a secreção de leite com um pico, por volta das 70 horas. A prolactina é produzida pela adenohipófise e está presente em níveis elevados podendo atuar junto dos receptores mamários e desencadeando a produção de leite. No entanto, a descida do leite depende da ocitocina. A sucção do bebê estimula múltiplas terminações nervosas presentes no mamilo produzindo impulsos sensitivos somáticos que são conduzidos ao hipotálamo e induz a produção de ocitocina para ejetar o leite (ÓRFÃO A, 2006). Dessa forma, neste estudo, ficou evidente o conhecimento de todos os profissionais entrevistados quanto a fisiologia da lactação.

Também foi observado na totalidade dos profissionais entrevistados que o tamanho das mamas não se relaciona com a sua capacidade funcional (CARVALHO MR e TAMEZ R, 2005). Todavia, em relação ao tipo de mamilo não interferir no sucesso da amamentação foi motivo de discrepância nas respostas, em que $40 \%$ afirmam interferir, outros $40 \%$ negam e $20 \%$ não souberam relatar. Porém, Galvão DMPG (2013), em seu estudo sobre o conhecimento da amamentação discutiu a presença de anomalias no mamilo relacionando com o desmame precoce devido a dificuldade de amamentar.

Diante dos princípios da técnica de amamentação inicialmente se instrui quanto a lavagem das mãos antes de iniciar (Sociedade Brasileira de Pediatria, 2012), a amamentação deve ser em livre demanda, sem horários pré estabelecidos, mas no tempo solicitado pelo bebê e a duração da mamada não é importante, segundo Levy L e Bertolo H (2008), entretanto Bueno LGS e Teruya KM (2004), a duração da mamada necessita de pelo menos 15 minutos para poder ser beneficiado pelo leite posterior, rico em gorduras e outros nutrientes. Assim sendo, diante das divergências literárias também foi possível observar tal discrepância neste estudo.

Quanto a lavagem das mamas deve-se utilizar apenas água, pois outros produtos podem ressecar os mamilos e causar fissuras (FERNANDES AT, et al., 2000). E no fim da amamentação devem ser aplicadas algumas gotas de leite retiradas na região mamilo areolar (BRASIL, 2009). Já o uso de pomadas ou cremes nos mamilos são contraindicados segundo Costa AA, et al. (2013). Tais questionamentos corroboram com a grande maioria dos indagados.

Em relação às contra indicações da amamentação são definitivas mães infectadas com o vírus do HIV, portadoras de Tuberculose ativa, doença grave, crônica ou debilitante e as que necessitam tomar medicamentos nocivos à criança (LEVY L e BERTOLO H, 2008). Já a Hepatite $\mathrm{B}$ e $\mathrm{C}$, e bebês com transtornos metabólicos (Fenilcetonúria e Galactosemia) não são contra indicações absolutas. 
No que se refere às mães portadoras de HIV, a amamentação atua como um meio de transmissão sendo porta de entrada pelas mucosas da nasofaringe e do trato gastrointestinal, estando associada a um risco de 29\% (Sociedade Brasileira de Pediatria, 2017). Ademais, tal afirmação também encontra-se no Ministério da Saúde. Mães portadoras de Tuberculose ativa são contra indicadas devido ao seu potencial de transmissão por meio de gotículas do trato respiratório (LAWRENCE RM, 2013). Quanto a Hepatite B e C, as mães que apresentarem fissuras nas mamas não podem amamentar devido ao contato que torna possível a transmissão (TITA ATN, et al., 2016).

Sendo assim, nesta pesquisa encontraram-se inúmeras divergências no que se refere às contra indicações do aleitamento materno, um total de $100 \%$ concorda com a contra indicação à mãe infectada por HIV e mãe que precisem de medicações nocivas à criança, $81,25 \%$ em mães com Tuberculose ativa, $73,33 \%$ em bebês com transtornos metabólicos, $53,33 \%$ em doenças crônicas, graves ou debilitantes da mãe e $50 \%$ em mães com Hepatite B e C. Dentre as razões que levam ao desmame precoce encontram-se uma série de fatores como a diminuição do leite, choro do bebê, cansaço materno, má progressão do peso da criança, ingurgitamento mamário, mastite e regresso da mãe ao corroborando com os resultados encontrados (SANDES AR, 2007).

Não obstante, quanto aos direitos maternos e paternos destaca-se a licença maternidade que no Brasil é de 120 dias, segundo o Art. 392 da Lei ํo 11.770/2008 da Consolidação das Leis do Trabalho (CLT), já a licença paternidade é de 10 dias, e em caso de gemelaridade, a licença maternidade passa para 180 dias segundo a Lei 2932/08. Pela CTL art. 396 a mãe deve ter dois períodos de 30 minutos cada para amamentar o seu bebê até que ele complete seis meses de vida. Quanto ao despedimento de trabalhadora grávida, puérpera ou lactante ou de trabalhador no gozo de licença parental carece de parecer prévio da entidade competente na área da igualdade de oportunidades entre homens e mulheres segundo o artigo $63^{\circ}$, proteção em caso de despendimento.

Logo, evidencia-se com os resultados obtidos que $86,67 \%$ concorda com a afirmativa do direito à proteção no despedimento das trabalhadoras em situação de gravidez, licença maternidade ou de amamentação, e com o direito de dispensa da mãe do trabalho, por dois períodos distintos de duração máxima de uma hora, durante todo o tempo que durar a amamentação, sem perder remuneração e/ou regalias, $80 \%$ concordam com o período da licença maternidade ser de 10 dias, $60 \%$ consideram incorreto o acréscimo de 30 dias por cada gêmeo além do primeiro, e 66,67\% julgaram incorreta a licença paternidade ser de 20 dias.

\section{CONCLUSÃO}

Profissionais atuantes na pediatria necessitam de uma educação permanente a respeito do aleitamento materno, uma vez que foi observada uma defasagem do conhecimento em relação a anatomia das mamas, às contra indicações do aleitamento materno e aos direitos da mãe e do pai durante o período de amamentação. Dessa forma, é sabido que uma capacitação de atualização possivelmente aumentaria os acertos sobre o conhecimento em aleitamento materno e transformará as práticas de promoção à saúde.

\section{REFERÊNCIAS}

1. ALDEN KK. Nutrição e Alimentação do Recém-Nascido. In: Bobak, M. Irene; Lowdermilk, L. Deitra; Perry, E. Shannon. O Cuidado em Enfermagem Materna. 5 ed. Porto Alegre: Editora Artmed, 2002; 445p.

2. AMITAY EL, KEINAN-BOKER L. Breastfeeding and childhood leukemia incidence: a meta-analysis and systematic review. JAMA pediatrics, 2015; 169(6):1-9

3. ARAÚJO MFM, et al. Custo e economia da pratica do aleitamento materno para a família. Rev. Bras. Saúde Matern. Infant., 2004; 4(2):135-141.

4. ARAÚJO RMA, ALMEIDA JAG. Aleitamento materno: o desafio de compreender a vivência. Revisa de Nutrição, 2007; 20(4): 431-438.

5. BARBOSA LA. Contato mãe-filho e amamentação na primeira hora de vida: avanços, desafios e influência da enfermagem. Trabalho de conclusão de curso (Bacharel em Enfermagem) - Faculdade de Ciências da Saúde. Universidade de Brasília (UnB), Brasilia, 2017;29p. 
6. BRASIL. Ministério da Saúde. Secretaria de Atenção à Saúde. Departamento de Atenção Básica. Saúde da criança: nutrição infantil: aleitamento materno e alimentação complementar. Brasília: MS;2015. 186p.

7. BRASIL. Ministério da Saúde. Secretaria de Atenção à Saúde. Saúde da criança: nutrição infantil aleitamento materno e alimentação complementar. Brasília: MS; 2009.112p.

8. BUENO LGS, TERUYA KM. Aconselhamento em amamentação e sua prática. Jornal de Pediatria, 2004; 80(5): 126130p.

9. CAMPOS DJ, BURNS DAR. Tratado de pediatria - Sociedade Brasileira de Pediatria. Barueri (SP): Manole, 2014; 2564p.

10. CARVALHO MR, TAMEZ R. Amamentação - Bases científicas para a prática profissional. Rio Janeiro: Guanabara Koogan, 2005; 452p.

11. COSTA AA, et al. Evidências das intervenções na prevenção do trauma mamilar na amamentação: revisão integrativa. Rev. Eletr. Enf, 2013; 15(3):790-801.

12. EUCLYDES M. Nutrição do lactente: bases científicas para uma alimentação saudável. Viçosa: UFV, $2005 ; 616 p$.

13. FERNANDES AT, et al. Infecção hospitalar e suas interfaces na área da saúde. São Paulo: Atheneu, 2000; $1812 p$.

14. GALVÃO DMPG. Conocimientos y actitudes de los estudiantes de enfermería frente a la lactancia. Revista de Psicología, 2013;1(2):769-782.

15. HORTA BL, et al. Long-term consequences of breastfeeding on cholesterol, obesity, systolic blood pressure, and type2 diabetes: systematic review and meta-analysis. Acta Paediatr., 2015; 104 (467): 30-7.

16. JOCA MT, et al. Fatores que contribuem para o desmame precoce. Escola Anna Nery, 2005; 9(3):356-364

17. LAWRENCE RM. Circumstances when breastfeeding is contraindicated. Pediatr Clin North Am., 2013;60(1):295-318.

18. LEVY L, BERTOLO H. Manual de Aleitamento Materno. Lisboa: Comité Português para a UNICEF, $2008 ; 44$ p.

19. LOTHROP H. Tudo sobre amamentação. Lisboa: Editora Paz, 2000; 349 p.

20. LUSTOSA E, LIMA RN. importância da enfermagem frente à assistência primária ao aleitamento materno exclusivo na atenção básica. ReBIS, 2020; 2(2):93-7.

21. MARQUES ES, et al. A influência da rede social da nutriz no aleitamento materno: o papel estratégico dos familiares e dos profissionais de saúde. Ciênc. saúde coletiva, 2010; 15(1):1391-1400.

22. MELO CS, GONÇALVES RM. Aleitamento Materno versus aleitamento artificial. Revista EVS, $2014 ; 41(1): 7-14$.

23. NEIVA FCB, et al. Desmame precoce: implicações para o desenvolvimento motor-oral. Jornal de Pediatria, 2003;79:1 12.

24. ÓRFÃO A. Avaliação dos primeiros 1000 casos do Cantinho da Amamentação. Revista APEO, 2006; 6:1-6.

25. ORGANIZAÇÃO MUNDIAL DE SAÚDE (OMS). Collaborative Study Team on the Role of Breastfeeding on the Prevention of Infant Mortality. Effect of breastfeeding on infant and child mortality due to infectious diseases in less developed countries: a pooled analysis. Lancet, 2000; I(355):451- 455.

26. PERES KG, et al. Effect of breastfeeding on malocclusions: a systematic review and meta-analysis. Acta Paediatrica, 2015; 104(467):54-61.

27. RABELO DA. Tratado de Pediatria-Sociedade Brasileira de Pediatria. 4⿳亠丷 Ed. Barueri (SP): Editora Manole, 2017; 2564p.

28. REZENDE MA, et al. O processo de comunicação na promoção do aleitamento materno. Rev Latino-am Enfermagem, 2002; 10(2):234-238.

29. ROLLINS NC, et al. Why invest, and what it will take to improve breastfeeding practices? The Lancet, 2016; 387(10017):491-504.

30. SANDES AR, et al. Aleitamento materno: prevalência e factores condicionantes. Acta Med Port., 2007; 20:193-200.

31. SOCIEDADE BRASILEIRA DE PEDIATRIA. Doenças maternas infecciosas e amamentação. Departamento Científico de Aleitamento Materno, 2017.

32. SOCIEDADE BRASILEIRA DE PEDIATRIA. Recomendações úteis para a manutenção do aleitamento materno em mães que trabalham fora do lar ou estudam. 2012.

33. SOUSA PKS, et al. Prevalência e fatores associados ao aleitamento materno na primeira hora de vida em nascidos vivos a termo no sudoeste da Bahia, 2017. Epidemiol. Serv. Saúde, 2020;29(2):2019-384.

34. TITA ATN, et al. Hepatitis B in pregnancy screening, treatment, and prevention of vertical transmission. Amercican J of Ostretrics \& Gynecology, 2016; 214(1): 6-14.

35. VICTORA CG, et al. Association between breastfeeding and intelligence, educational attainment, and income at 30 years of age: a prospective birth cohort study from Brazil. The lancet global health, 2015; 3(4):199-205.

36. ZUTIN TLM. A posição do homem no processo de amamentação: um ensaio sobre a produção de sentidos. Tese (Doutorado em Ciências) - Escola de Enfermagem de Ribeirão Preto. Universidade de São Paulo, 2012; 128p. 